\title{
AN ANALYSIS OF BASIC PARAMETERS OF RO-PAX FERRIES IN THE BALTIC SEA AS GUIDELINES FOR ITS PRELIMINARY DESIGN
}

\author{
Lucjan Gucma \\ Julia Raczkowska \\ Maritime University of Szczecin, Poland
}

\begin{abstract}
This paper presents results of an analysis of the operating and maneuvering parameters (length, width, draft, main propulsion power and maneuvering equipment, and windage area) of the Ro-Pax ferries over $150 \mathrm{~m}$ in length. The analysis takes into accounts all ferries operating in the Baltic Sea in 2017. The work also includes route analysis of the collected Ro-Pax units. The influence of port infrastructure is also discussed. The mean optimal Baltic Sea Ro-Pax ferry and its parameters for short term and long term forecasts are presented. This paper may be used as a primary guideline for the determining the optimal Ro-Pax ferry dimensions size for the Baltic lines in terms of preliminary ship design.
\end{abstract}

Keywords: Ro-Pax ferry, ship design, ferry traffic, operating parameters, maneuvering parameters, analysis of ship dimensions

\section{INTRODUCTION}

Ship design is a complex process, consisting of several subsequent stages, compliant with Evans's rule of design helix, and elaborated by Andrews in terms of helix loops. (Charchalis \& Krefft, 2009) The essence of this design approach is illustrated in the Fig. 1. The expected solution is reached by verifying design decisions made at the preliminary design phase in the progressive course of design process. Traditionally, ship design may be considered in the four main phases process, namely:

1. Concept design - Feasibility study;

2. Preliminary design;

3. Contract design; and

4. Detailed design (Papanikolaou, 2014).

Early stages of each modern ship design are concept design - feasibility study and preliminary design, also known as basic design (Papanikolaou, 2014). The base for ship design are very precisely defined in client's requirements. They are prepared in form of technical and economical features of future ship. Next, client's assumptions are checked for compliance with restrictions on the length, beam and draft in terms of the passage of canals and channels, ship's approach to river estuaries, and calling at certain ports. The preliminary ship design encompasses the following more detailed objectives: Selection of main ship dimensions; Development of the ship's hull form; Specification of main machinery and propulsion system type and size; Estimation of auxiliary machinery type and powering; Design of general arrangement of main and auxiliary spaces (cargo spaces, machinery, spaces and accommodation); Specification of cargo-handling equipment; Design of main structural elements for longitudinal and transverse strength; Control of floatability, stability, trim and freeboard, and Tonnage measurement (Papanikolaou, 2014).

The concept phase, which generally is an iteration process, plays a critical role in the final project results. This process requires the repetition of a single analysis procedure, or sometimes even all cycles, several times. The empirical equations form the base for analytical methods. They are usually determined using regressive analysis of collected data on similar, significant ships. The mathematical relationships between different dimensions, parameters and features 
of specified type of vessel are shown in these equations. (Charchalis, 2013) The verification based on contemporary significant ship database is the key to achieve the reliable accuracy of analytical methods. Iteration methods require application of data coming from the significant ships database. The obtained relationships, which comply with the client's ship assumptions and main dimensions coming from similar ship database, are used to determine general dimensions of the designed ship, and are the basis for further optimization studies. This stage gives fundamental data on ship design, like her main dimensions, hull form or powering, which have strong influence on further ship design and project cost, and consequently construction and exploitation costs. Any changes of ship data specified at this phase made at later stages can entrain great expenses for shipowner.

The contract design phase aims to prepare all necessary calculations and naval architectural drawings, as well as the drawing up of the technical specifications of the designed ship. The documents are the base for the formal shipbuilding contract between the ship owner and the shipyard.

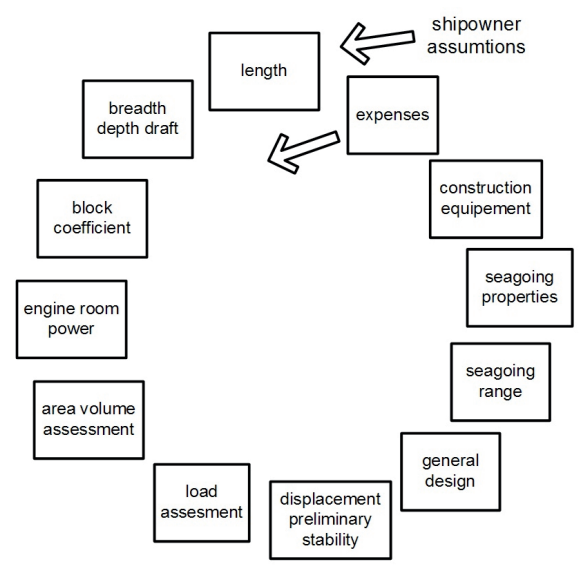

Fig. 1. The Andrews - Evans design helix (Andrews, D. J., 1985; Evans, J. H., 1959; Iza, V., 2003)

\section{SHIP DESIGN DATA}

The initial design phase is significantly based on data gathered from preexisting implemented ship designs and existing ships themselves, similar to the vessel being designed. More specifically, using statistical methods, dimensions and their corresponding relationships with the designed ship, the collected data is used. In the past, most of the information was obtained from articles in the technical press (i.e. R.I.N.A's Significant Ships series). The design information, usually including plans, published in these articles are based on data provided by the shipbuilders. The main and fundamental data source is a company ship database built based on information about ships which have been designed, built, or owned by the companies for whom the data collector works. The majority of companies create and update a comprehensive ship database including the calculations, plans, specifications, tank test results, trial trip reports, material orders, man-hours and cost data. Asides from the design department's records, a prime source of data on the dimensions of almost all types of ships is Lloyd's Register. It provides extensive information about all sea-going, selfpropelled merchant ships of $100 \mathrm{GT}$ and above, irrespective of their classification. The most significant advantage of this data, in comparison to data obtained from articles in the technical press and similar sources is that it's provenance guarantees its complete confidence. The collected information relates mostly to: ship dimensions and dimensional ratios; ship's lines, with block coefficient and LCB position, etc.; powering; general arrangements; steel-weight, outfit weights and machinery weights; areas and volumes; the many rules applicable to ships; the many different items that make up outfit with notes on their capabilities, weights and the services they require; cost data of all sorts (Watson, 1998).

The most significant benefit of well organized ship database infrastructure and proper software is that, the feasibilityconcept design may be accomplished in 1 day or even less. (Papanikolaou, 2014)

This paper and the information held within it could be used as a method for preparing a primarily analysis for further studies aimed at designing new Ro-Pax vessels and predicting the trends of ship designing development.

\section{SELECTION OF FERRY'S MAIN DIMENSIONS}

The design of ships dimensions is always a compromise between ship owner's requirements, legal and technical restrictions and waterway and infrastructure limitations. When determining the main dimensions of ship, beam and draft in particular, topological limits of the route acts as a boundary line, often dictating the result value.

There are six dimensional relationships linking the four main ship dimensions of length, beam, depth and draft. To solve either the weight or volume equations three of these have to be used. The relationships are (Bertram, 2000):

$$
\begin{aligned}
& B=f(L) \quad D=f(L) \\
& D=f(B) \quad T=f(L) \\
& T=f(D) \quad T=f(B)
\end{aligned}
$$

where:

$B$ - beam $[\mathrm{m}]$;

$T-$ draft $[\mathrm{m}] ;$

$L$ - length [m]; and

$D$ - depth [m].

For the economy of construction, a ship should be perceived as a container. As the straight-side container which has the least surface area for a given volume is a cube, therefore, the vessel, according to this approach, should be as closely as 
possible to this shape. This approach, according to (Watson, 1998), requires that draft (the smallest of the dimensions) should be the maximum permitted by length, breadth and depth; that depth (the next smallest dimension) should be the maximum permitted by length and breadth; that breadth should be the maximum permitted by length and finally that the block coefficient $C_{B}$ should be as full as possible.

Designing a new vessel usually starts with determining the ship's length. The length is usually specified based on similar ship data derived from a ship design database. In the case of deadweight carriers, next the displacement is estimated. After the preliminary estimation of the ship's length as well as the block coefficient $C_{B}$, the ship's width in relation to the draft is determined. These dimension are directly connected with each other through following formula:

$$
B \cdot T=\nabla /\left(L \cdot C_{B}\right)
$$

where:

$B$ - beam $[\mathrm{m}]$;

$T-\operatorname{draft}[\mathrm{m}]$

$L$ - length $[\mathrm{m}]$; and

$C_{B}-$ block coefficient [-].

If neither restricted nor limited, the choice of proper width values usually results from the stability demands. Draft, which must correspond to the formula 4 , it is chosen in relation to the width such that the desired degree of stability results. For ships with restricted dimensions (particularly draught), the width required for stability is often exceeded. (Schneekluth \& Bertram, 1998) Correlation between coefficients $L / B$ and $B / T$ are essential to define the impact of specified dimensions in ships. Coefficient $B / T$ effects transverse stability of the ship and her hydrodynamic performance. Increasing of breadth has a positive influence on stability. However, it also increases resistance of a hull and requires higher propulsion power. $L / B$ has impact on hull resistance and therefore its power. In terms of ship stability, the $L / B$ ratio is less significant than the $B / T$ ratio.

\section{BASIC DESIGN DATA OF RO-PAX FERRIES WITH CONSIDERATION OF PORT INFRASTRUCTURE}

The main design parameters of ferries are discussed below and their importance in terms of matching the ferry to the existing port infrastructure. The basic ferry operational parameters influencing predesign are (Gucma S., 2012):

1. total length (Loa),

2. breadth of the ferry $(B)$,

3. draft of the ferry $(T)$,

4. transverse windage area $\left(F_{y n}\right)$,

5. power of the main propulsion $(P)$,

6. power of side thrusters $\left(P_{s s}\right)$,

7. type of propulsion and steering devices.

The total length $\left(L_{o a}\right)$ is the most important parameter of the Ro-Pax ferries, because it influence the loading capacity (length of the load line). From the navigational and operational point of view, the length of the ferry determines the necessary length of the mooring line of the quay. In most cases, the $L_{o a}$ of the ferry should be shorter than the existing length of the quay, so that it is possible to provide proper angle of bow or stern lines. The length of the ferry also determines the minimum diameter of the turning place in the port. The minimum diameter of the turning place should be $1.5 L_{o a}$, however in special cases, the ferry is able to turn within a smaller area, i.e. up to $1.2 L_{o a}$, but this should be confirmed by individual tests usually carried out using simulation methods. Determining the minimum maneuvering area in this case involves the necessity to carry out real time maneuvering simulation tests under varied conditions.

The ship's breadth $(B)$ is a parameter, which for Ro-Pax ferry is not very variable when changing the length of the ferry. It influences mainly on the speed characteristics of the ferry (appropriate slenderness) and, above all, on the number of loading lines per car deck. Typically, the width of a single load line lane for heavy goods vehicles is set at $3.1 \mathrm{~m}-3.6 \mathrm{~m}$. Narrowing the car lines increases the total length of the load line, but may cause difficulties in loading (increased loading time) and more difficult access in case of fire. In terms of the maneuvering area for the ferry, the width determines the minimum width of the approach waterways to the terminal. The minimum width of the waterway is defined as the multiplicity of the unit's width and is taken as a value from $2 B$ (or sometimes even less) to even $4 B$ depending on the navigational conditions and the type of the water body. The average width of large Ro-Pax ferry is around $B \approx 28 \mathrm{~m}$. Such widths in the analyzed ports (Świnoujście, Ystad, Trelleborg) do not affect the restriction in this respect, therefore it can be considered as irrelevant in terms of navigation.

Draft of the ferry $(T)$ is assumed that the safe depth of the basin should allow the ferry to enter with adequate reserve for water levels decrease. Significant squat of the ferry should be taken into account, because in difficult conditions, to keep the right momentum of the maneuver captain should maintain a significant speed (even up to 7 in) when entering the port. Ro-Pax ferries, however, due to the spatial cargo have relatively low draft compared to other types of ships of similar length. These values reach up to approximately $T=6.5 \mathrm{~m}$ and do not cause significant navigation restrictions at medium water levels in the majority of Baltic Sea ports.

The transverse windage area $\left(F_{y n}\right)$ is the result of providing adequate dimensions of the ferry and struggling to increase the space for the spacious ro-ro cargo and passengers, which highly increases the windage area. Properly selected parameters of the main and auxiliary propulsion enable, in turn, keeping the maneuverability of the ferry under given operating conditions.

The total power main propulsion $(P)$ is selected to ensure the right speed characteristics. The power of propulsion devices also determines with the power of additional steering gears the possibility of independent maneuvering, including mainly overcoming by the ferry of aerodynamic drag, which is 
related to the windage area of the ferry. Power of side thrusters $\left(P_{s s}\right)$. In most large Ro-Pax units, in order to generate forces and moments in the ship forebody (or balancing the moments in the stern section), a set of bow thrusters on (1 to 3) or stern thrusters (usually maximum 1 stern rudder) is used for maneuvers without using the tugs.

The following types of propulsion and steering devices are most frequently used on Baltic Ro-Pax ferries are:

1. classical: aft - two controllable pitch propellers (CPP), two unconventional rudders placed behind the propellers (usually active Becker style), optional stern thrusters; bow - bow thruster or thrusters (approximately on over 90\% of ferries);

2. azimuth: aft -2 azimuth propulsors (both gondola type and without gondola) placed on the extreme sides of ferry (less than $10 \%$ of ferries), bow - bow thrusters;

3. azimuth propulsors used on two-sided ferries (one or two on the bow and same on stern);

4. others, such as the VS drive, very rare on ferries.

To determine the operational parameters for ferries an individual method is used, which consists in analyzing a given ferry in relation to a given position and determining extreme conditions (wind force, current speed and direction etc.).

\section{MAIN ROUTES AND FERRY TRAFFIC IN THE BALTIC SEA}

As the question of the actual borders of the Baltic Sea Region remains open, for the purpose of this research, we include ten countries featuring their coastlines along both the Baltic Sea and Skagerrak Strait. These are (in alphabetical order): Denmark, Estonia, Finland, Germany, Latvia, Lithuania, Norway, Poland, Russia and Sweden. Based on given assumptions, the data were collected from two databases (http://matkustajalaivat.com, www.ferry-site.dk). The total of 62 ferries, operated by 16 ferry companies, were listed and processed statistically. The Fig. 2. illustrates the analysis of number of the operators' fleet.

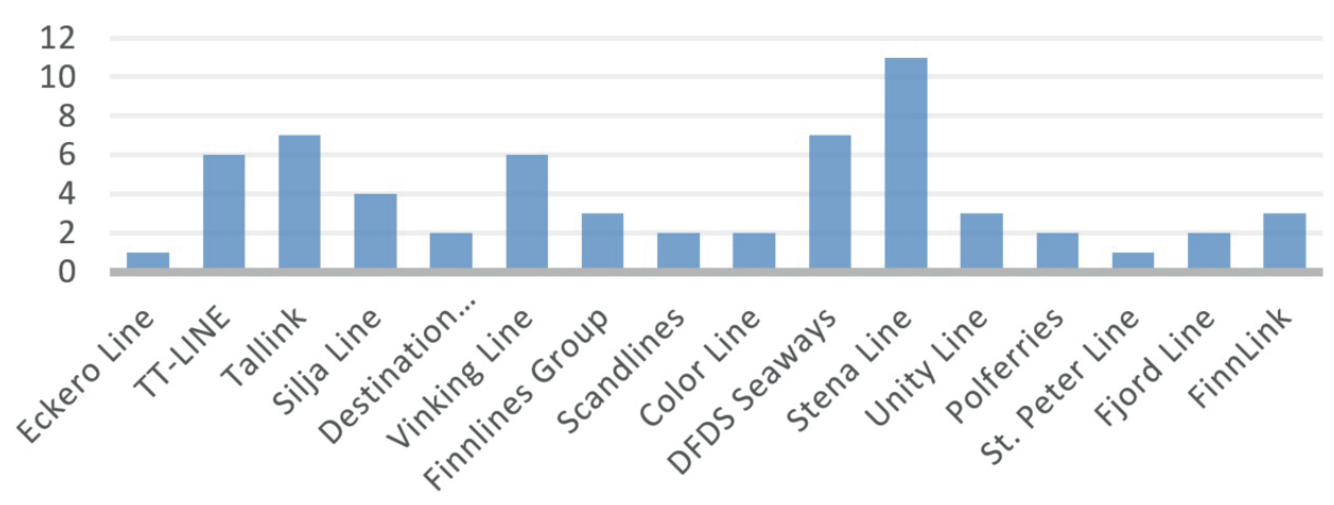

Fig. 2. The analysis of number of the operators' fleet
Baltic ferry operators currently serve 29 independent lines. The vast majority of the routes (97\%) are international connections. The only domestic route is the connection between Swedish island Gotland and the port of Nynäshamn on the mainland. As a matter of fact, there are far more domestic lines connecting Swedish, Danish, Norwegian islands with their respective mainland's. However, they are served by small local ferries operators with fleet usually under $150 \mathrm{~m}$ in length. The Fig. 3. gives an overview of the Ro-Pax ferry connections in the Baltic Sea as of 2015.

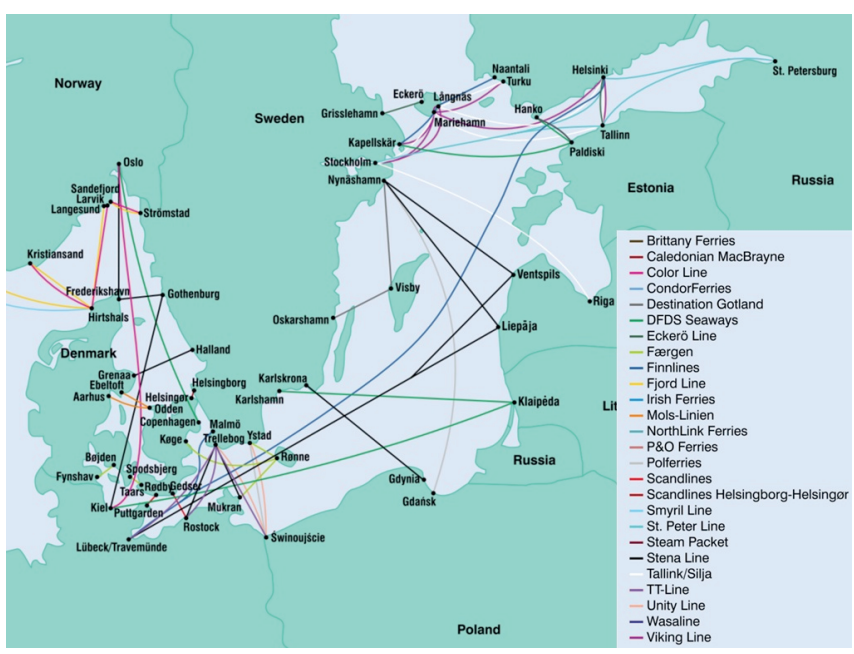

Fig. 3. The map of Ro-Pax ferry connections in the Baltic Sea as of 2017 Ro-ro \& ferry (atlas Europe 2016/2017)

According to collected data, Swedish ports handle nearly $71 \%$ of all Ro-Pax ferries' Baltic voyages, what makes them the busiest in the BSR. This is not surprising, as Sweden has been the leader among the BSR countries in terms of the number of ferry connections with other countries of the Baltic Sea for many years. (Uriasz, 2010; Wiskulski, T. \& Bar-Kołelis D., 2012) Sweden has developed ferry connections with nearly all Baltic countries, except for Norway and Denmark, thanks to a great number of ferry ports (11 ports listed). The most used Swedish routes lead to Germany, Finland and Poland (5, 4 and 4 routes respectively). Other rather traffic-dense BSR are Danish Straits and Kiel Canal. Denmark and Norway are connected by five different routes. However, these lines are often serviced by only one ferry.

The busiest international routes are Helsinki Tallinn and Trelleborg - Rostock links. Both connections are serviced by 6 different ferries of 4 and 2 different operators respectively. Other very popular routes connect Stockholm with Finnish cities - Helsinki and Åbo. 4 different ferries of 2 different 
ferry companies operate on these lines. The only connection with Russian port is St. Petersburg - Helsinki - Stockholm - Tallinn route served by a cruise Ro-Pax ferry of St. Peter Line Company. A little more than $40 \%$ of all BSR connections is serve by only one Ro-Pax ferry. This concerns mostly traffic between Sweden and Baltic States, and Denmark and Germany.

\section{INFLUENCE OF PORT INFRASTRUCTURE ON PRELIMINARY FERRY PARAMETERS}

Very specific in Ro-Pax ferry trade is strong influence of the existing and planned port infrastructure on design parameters. The major parameter here is length of the ferry quay $(L)$ which will affect possibility of mooring of given ships. Another aspect is the turning possibility that is obviously the function also of ferry length (Gucma L., 2010). Table 2 presents of existing and planned parameters of three ports for operation of Ro-Pax ferry considered in this study.

Tab 1. Chosen quay parameters (length) for considered ferry

\begin{tabular}{|l|c|c|c|}
\hline \multicolumn{1}{|c|}{ Port } & Świnoujście & Ystad & Trelleborg \\
\hline $\begin{array}{l}\text { Existing quays } \\
\text { of } 150 \mathrm{~m}<\mathrm{L}<200 \mathrm{~m}\end{array}$ & 4 & 1 & 6 \\
\hline $\begin{array}{l}\text { Existing quays } \\
\text { of } 200 \mathrm{~m}<\mathrm{L}<230 \mathrm{~m}\end{array}$ & 1 & 2 & 1 \\
\hline Existing quays of $\mathrm{L}>230 \mathrm{~m}$ & 0 & 0 & 1 \\
\hline $\begin{array}{l}\text { Planned quays of } \mathrm{L}>230 \mathrm{~m} \\
\text { (within 3 years) }\end{array}$ & 1 & 3 & 3 \\
\hline
\end{tabular}

\section{ANALYSIS OF SELECTED PARAMETERS OF RO-PAX FERRIES CURRENTLY OPERATING IN THE BALTIC SEA}

The sample size covered by Baltic Sea operating ferry parameters. The data was collected in the beginning of 2017. Sample covers 62 ferries operated on the Baltic Sea at the beginning of 2017. Only ferries with a length of more than $150 \mathrm{~m}$ were considered. It should be noted that ferry lines are often handled by sister units. Consequently, the sample size is reduced. The presented ferry parameters analysis allows to determine the average parameters of ferry currently operating, the ferry development trends in the Baltic Sea and indispensable power for equipment for controlling ship's movements depending on the ferry's dimensions. The following parameters of the vessels were analyzed:

- building year $-b / y$,

- length overall $-L_{o a}[m]$,

- bream - B [m],

- draft - T [m],

- main propulsion power - $P[k W]$,

- thunders power $-P_{s s}[k W]$,

- transverse windage area $-F_{n y}\left[m^{2}\right]$.

Table 2 presents selected quantitative statistical parameters of the examined data in the form of measurements of central values, variations, symmetry and concentration.
Tab 2. Quantitative analysis of selected vessel parameters

\begin{tabular}{|l|c|c|c|c|c|c|c|}
\hline Parameter & $\mathrm{b} / \mathrm{y}$ & $\mathrm{L}_{\text {oa }}[\mathrm{m}]$ & $\mathrm{B}[\mathrm{m}]$ & $\mathrm{T}[\mathrm{m}]$ & $\mathrm{P}[\mathrm{kW}]$ & $\mathrm{P}_{\mathrm{ss}}[\mathrm{kW}]$ & $\mathrm{F}_{\mathrm{ny}}\left[\mathrm{m}^{2}\right]$ \\
\hline Sample size & 62 & 62 & 62 & 62 & 62 & 34 & 62 \\
\hline Minimum & 1980 & 152.2 & 23.7 & 4.8 & 13020 & 1000 & 3140 \\
\hline Maximum & 2014 & 243.3 & 32 & 7.416 & 50400 & 9300 & 6800 \\
\hline Mean & 1998 & 187.95 & 27.79 & 6.40 & 27097.61 & 2981.65 & 4585.81 \\
\hline Median & 1999 & 186.21 & 27.7 & 6.4 & 25200 & 2601 & 4500 \\
\hline Quartile 1 & 1990 & 174.67 & 26.45 & 6.22 & 22400 & 2200 & 3700 \\
\hline Quartile 3 & 2000 & 198.99 & 29 & 6.70 & 31021 & 3261.5 & 5037.5 \\
\hline Standard deviation & 9.21 & 17.83 & 1.95 & 0.48 & 9192.07 & 1521.21 & 934.80 \\
\hline Skewness coefficient & -0.17 & 0.87 & 0.03 & -0.63 & 1.12 & 2.54 & 0.62 \\
\hline Relative kurtosis & -1.03 & 1.06 & -0.13 & 1.77 & 1.093 & 8.57 & -0.39 \\
\hline
\end{tabular}

From the data in Table 2 we can see the mean values of each, examined vessel parameters. The data indicate that the average Baltic Ro-Pax ferry is 19 years old, $188 \mathrm{~m}$ long, $28 \mathrm{~m}$ wide and $6.4 \mathrm{~m}$ deep. Her main propulsion power is $27,100 \mathrm{~kW}$, her stern and bow thunders power is $3,000 \mathrm{~kW}$ and her topside projected area is $4,600 \mathrm{~m}^{2}$.

The standard deviation values show relatively small statistical dispersion from mean value of all analyzed operating parameters. A similar situation occurs in the case of the kurtosis values, which suggest slight skewness of analyzed parameters' values. Merely the kurtosis values for vessel main power indicate significant differences between the normal distribution and the kurtosis estimator, which results from a large number of vessels with an engine of the power ranging from $20,000 \mathrm{~kW}$ to $30,000 \mathrm{~kW}$.

\section{VESSEL'S YEAR OF BUILD}

It should be noted that the mean age of Ro-Pax ferries currently operating in the Baltic Sea is around 18 years. The detailed frequency distribution of ferries in the form of a histogram is shown in Fig. 4. An analysis of data shows that a significant number of ferries was built between 1985 and 1995 (22 vessels). These are vessels that need replacing with newer ones. It can be seen that in 2005-2010 a considerable number of new ferries (16 vessels) were placed into service.

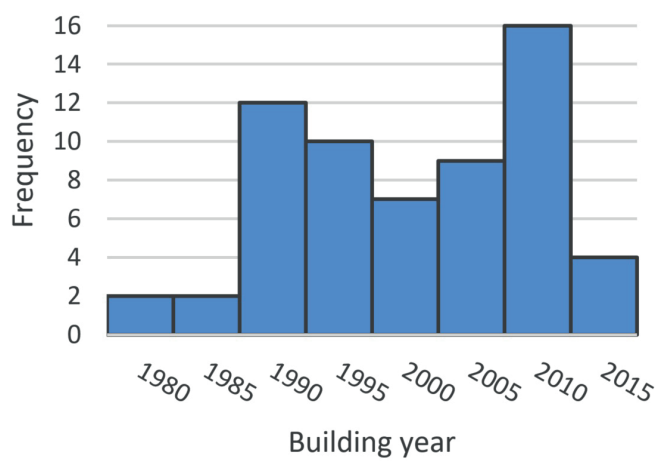

Fig. 4. Analysis of the age of Baltic ferries (as of 2017)

The changing dynamics of length overall in relation to the building year of ferries in the Baltic Sea (Fig. 5) shows no significant changes over time. The average ferry length grow is only $0.86 \mathrm{~m}$ per year. This is caused by the market demand and the slow expansion of port infrastructure, which has an 
average lifespan in excess of 25 years. At that time of lifespan, the average length of the ferries in the Baltic Sea has increased by only $21 \mathrm{~m}$. In the Fig.5. one can also notice a group of several new ferries, built between 2005 and 2010, whose average length is approximately $200 \mathrm{~m}$ if not slightly less.

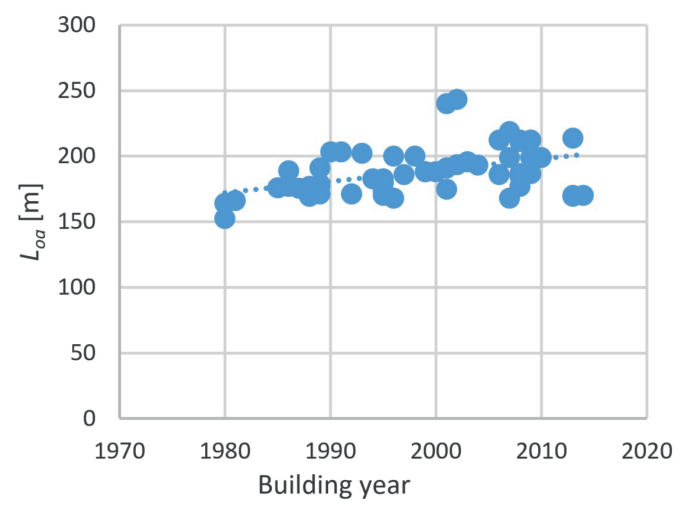

Fig. 5. Changing dynamics of length overall $\left(L_{o a}\right)$ of Baltic ferries in relation to their building year (as of 2017)

\section{VESSEL'S LENGTH}

The length overall (Loa) of the ferries is shown as the frequency distribution in Fig. 6. It can be seen that a significant part of the units are from $170 \mathrm{~m}$ to $200 \mathrm{~m}$ (39\%). Ferries of $200 \mathrm{~m}$ to $220 \mathrm{~m}$ make up only $16 \%$. Ferries over $230 \mathrm{~m}$ are a rarity. This is mainly due to the fact, that port infrastructure is not properly prepared to receive such ships.

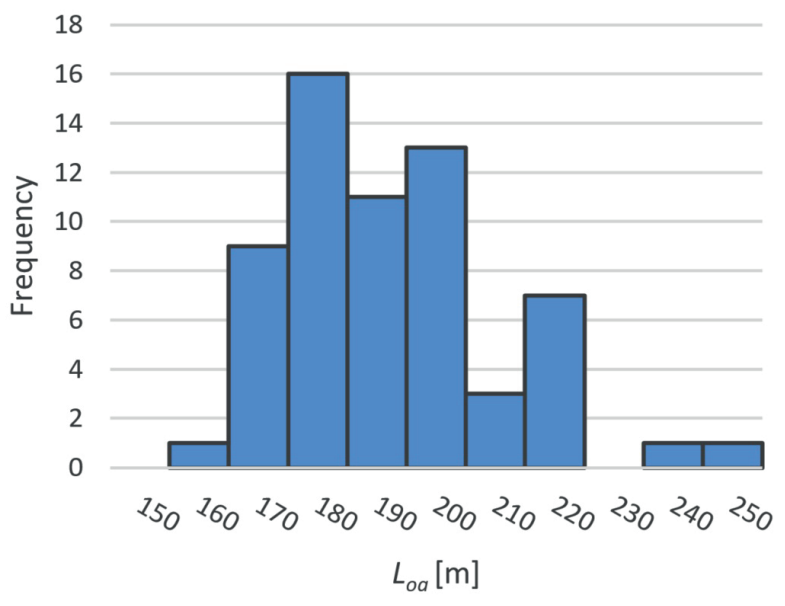

Fig. 6. Analysis of length overall $\left(L_{o a}\right)$ of Baltic Ferries (as of 2017)

\section{VESSEL'S BREADTH}

A histogram of the vessel's breadth is presented in Fig. 7. The average breadth of ferries with length overall over $150 \mathrm{~m}$ is $B=28 \mathrm{~m}$ and the ferries with width ranging from $27.5 \mathrm{~m}$ to $29.0 \mathrm{~m}$ make up the majority (42\%). Noteworthy, ferries rarely exceed $30 \mathrm{~m}(11 \%)$.

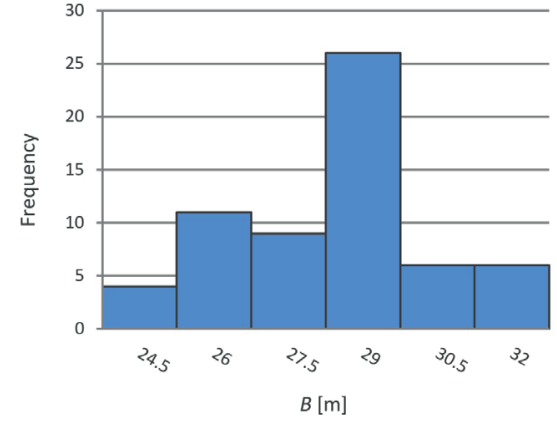

Fig. 7. Analysis of width (B) of Baltic Ferries (as of 2017)

Though the analysis of the ferries' breadth (Fig. 7) indicates a small effect of the length of ferries on their breadth, all of the ships are within the coefficient $L / B$ range for fast and passenger vessels, which value ranges between 6.5 and 8.5 .

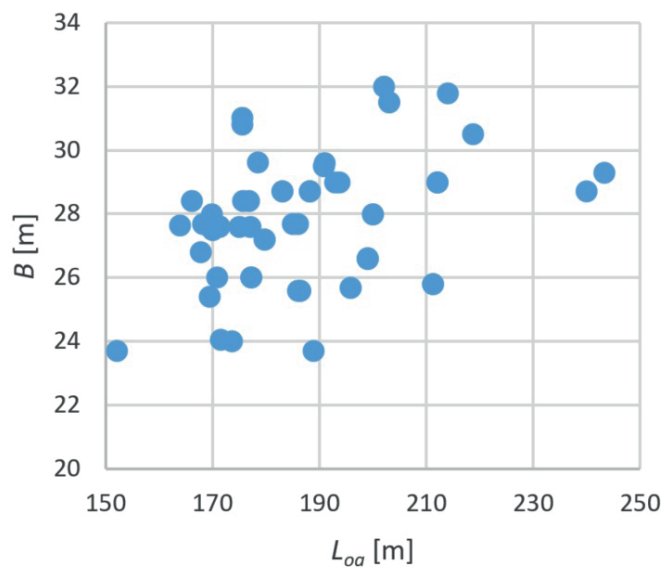

Fig. 8. Analysis of width $(B)$ as a function of length overall $\left(L_{o a}\right)$ of Baltic ferry (as of 2017)

\section{VESSEL'S DRAFT}

Analysis, in a form of histogram, of draft $(T)$ of the ferries is shown in the Fig. 9. It indicates that the draft of significant part of the vessels ranges from $6.2 \mathrm{~m}$ to $6.9 \mathrm{~m}$ (66\%). The average draft of Baltic Ro-Pax is about $6.4 \mathrm{~m}$ and rarely exceeds $6.9 \mathrm{~m}(11 \%)$.

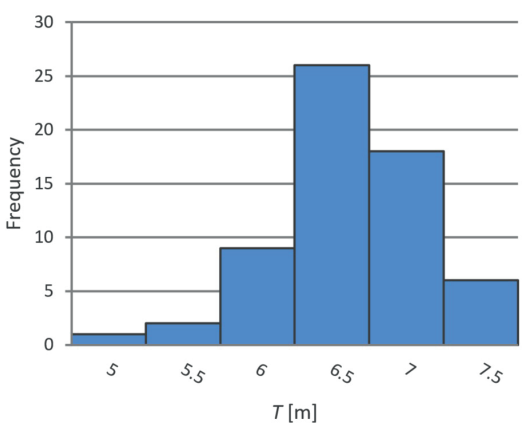

Fig. 9. Analysis of draft (T) of Baltic Ferries (as of 2017) 
The $L / T$ ratio is essentially a secondary relationship resulting from formula in 4 . Analyzing ferry's draft one comes to similar conclusions as in the case of the width (Figure 8). Vessel's draft does not depend significantly on its length overall.

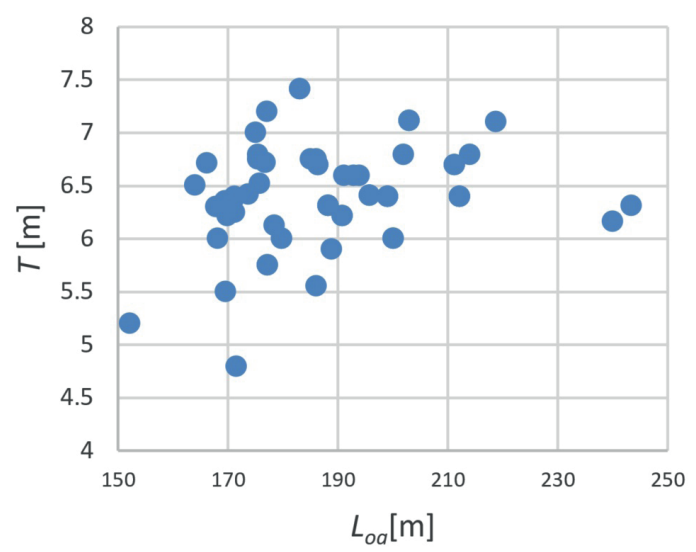

Fig. 10. Analysis of draft $(T)$ as a function of length overall $\left(L_{o o}\right)$ of Baltic ferries (as of 2017)

\section{VESSEL'S PARAMETERS INFLUENCING ITS MANEUVERING POSSIBILITY}

The transverse windage area of the ferry $\left(F_{y n}\right)$ is a basic parameter that determines the vessel's maneuverability and power requirements for self-maneuvering. There is a strong correlation between a topside projected area and length overall of the ferries. This phenomenon was proven in the Fig. 11.

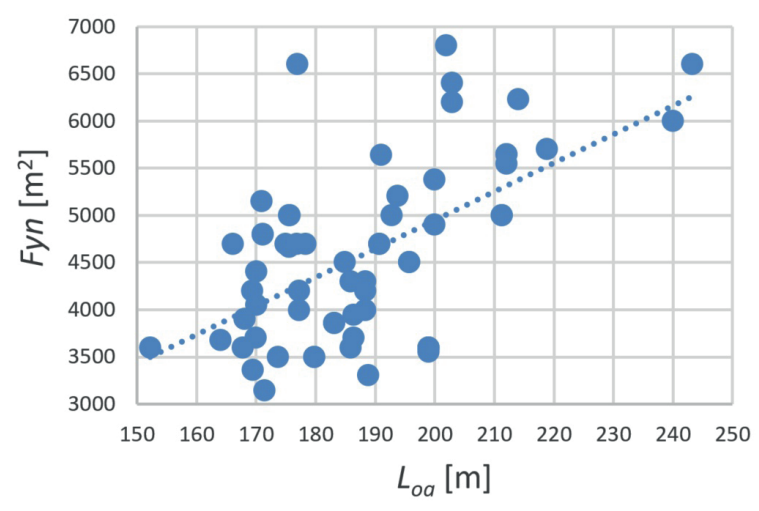

Fig. 11. Correlation of the topside projected area of the ferry $\left(F_{y n}\right)$ from the length overall $\left(L_{o a}\right)$ of the Baltic ferry (as of 2017)

Figure 12 presents the dependence of the total power of the main propulsion $(P)$ on the transverse topside projected area $\left(F_{n y}\right)$ of the Baltic ferries. It shows a strong correlation between these parameters, not including fast ferries, which were designed for speeds higher than average $\left(V_{r s}=22 \mathrm{kn}\right)$.

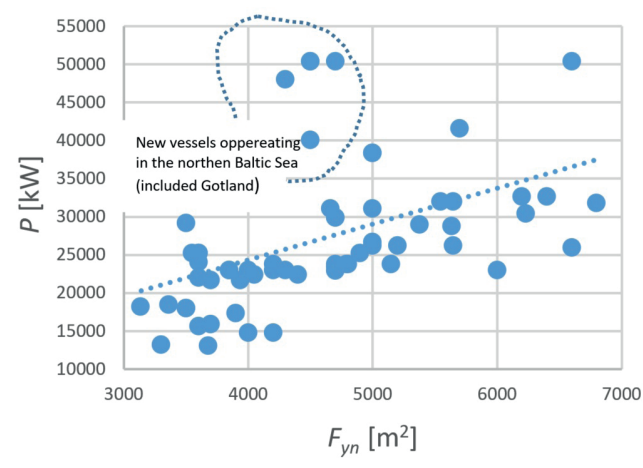

Fig. 12. Correlation of main propulsion power $(P)$ from transverse windage area of the ferry $\left(F_{y n}\right)$ of the Baltic ferry (as of 2017)

Transverse windage area of the ferry $\left(F_{y n}\right)$ of the ferries is shown as the frequency distribution in the Fig. 13. It can be seen that a significant part of the units range from $4,000 \mathrm{~m}^{2}$ to $5,0000 \mathrm{~m}^{2}$. The histogram slightly corresponds with an analysis of ferries' length overall $\left(L_{o a}\right)$, as there is a correlation between these two parameters.

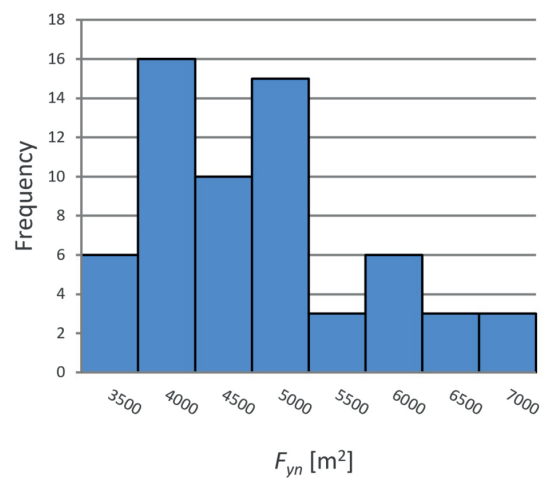

Fig. 13. Analysis of transverse windage area of the ferry $\left(F_{y n}\right)$ of Baltic Ferries (as of 2017)

An analysis main propulsion power $(P)$ of Baltic Ferries is illustrated in the Fig. 14, including a bar chart. An analysis of data in figure above shows that the most frequently present in the BSR vessels were those propelled by an engine with power ranging from $20,000 \mathrm{~kW}$ to $30,000 \mathrm{~kW}$, as they account for nearly $55 \%$ of all vessels.

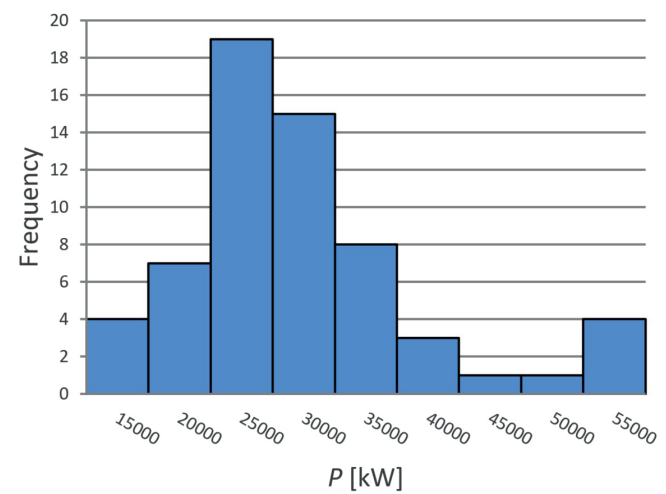

Fig. 14. Analysis of main propulsion power (P) of Baltic Ferries (as of 2017) 
The dependence of the total power of bow and stern thunders $\left(P_{s s}\right)$ from length overall is shown in the Fig. 15. It indicates the correlation between a thunder power and a ferry's length. This is understandable, as they are designed to balance wind torque, which increases with a vessel's length.

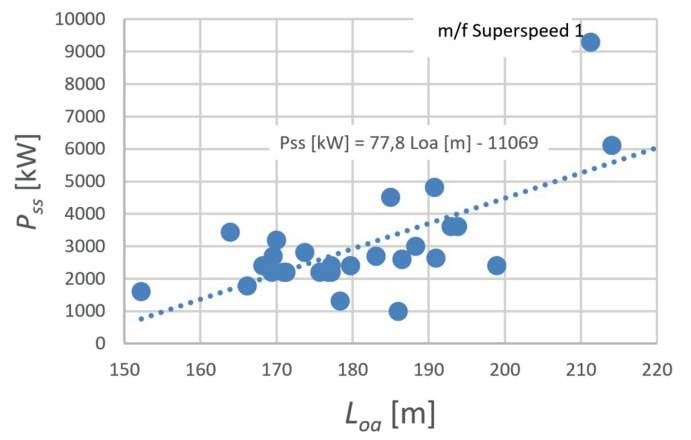

Fig. 15. Correlation of total power of bow and stern thrusters $\left(P_{s s}\right)$ from length overall $\left(L_{o \alpha}\right)$ of Baltic ferries (as of 2017)

Figure 16 presents an analysis of total power of bow and stern thunders $\left(P_{s s}\right)$ of Baltic Ferries It shows clearly a greater number of vessel with total power of bow and stern thrusters between $3,000 \mathrm{~kW}$ and 4,000 kW, as they account for nearly $69 \%$ of all vessels. Vessels equipped with bow and stern thrusters of power over $7,000 \mathrm{~kW}$ are a rarity $(6 \%)$.

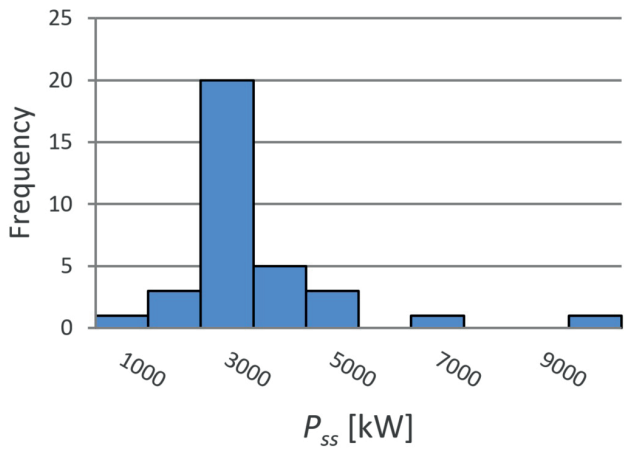

Fig. 16. Analysis of total power of bow and stern thunders $\left(P_{s s}\right)$ of Baltic Ferries (as of 2017)

\section{DETERMINATION OF FUTURE MEAN FERRY PARAMETERS}

Statistical analysis of selected parameters of ferries currently operating on the Baltic Sea leads to the conclusion that the medium, future-oriented ferry on the Baltic Sea is a ship with the following parameters:

Name: Ro-Pax200m

$L_{o a}=200 \mathrm{~m}$

$B^{o a}=28 \mathrm{~m}$

$T=6.5 \mathrm{~m}$

$F_{n y}=5.000 \mathrm{~m}^{2}$

$P^{n y}=27,000 \mathrm{~kW}$

$P_{s s}=4,000 \mathrm{~kW}$
By assuming that the dynamics of infrastructure development will not change significantly, it will be able to be operated for about 25 years. Such a ferry will be able to use the existing infrastructure in the Baltic Sea during that time and can be easily moved over Baltic Sea lines.

As a maximum ship - the future one, which will be able to be served only in some ports and will be slowly coming into operation over next 10 years is Ro-Pax with the parameters:

Name: Ro-Pax300m

$L_{\text {oa }}=230 \mathrm{~m}$

$B=30 \mathrm{~m}$

$T=6.7 \mathrm{~m}$

$F_{n y}=5,800 \mathrm{~m}^{2}$

$P=33,000 \mathrm{~kW}$

$P_{s s}=6,000 \mathrm{~kW}$

\section{CRITICAL WIND SPEED FOR FERRY OPERATION}

Critical wind speed $\left(v_{k}-\right.$ the maximum transverse wind speed for safety operation) is a crucial parameter for Ro-Pax ferries determining the no-delay operation. Expert investigations have been made to determine parameters of critical wind speed by ferry captains. The values are subjective but its estimation is averaged by ferry crew in long time operation experience. The Tab. 7 shows these critical wind speeds $\left(v_{k}\right)$ for safe operations of various ferries exploited in the South-West Baltic area. The linear model is created to establish dependence of such an indicator on the critical speed of the ferry (Fig.15) in form:

$$
v_{k}=f\left(\frac{c_{p}}{F_{y n}}\right)=f\left(\frac{P+k P_{S S}}{F_{y n}}\right)
$$

where:

$v_{k}-$ critical speed $[\mathrm{m} / \mathrm{s}]$

$P$ - main propulsion power $[\mathrm{kW}]$;

$P_{s s}$ - total power of thrusters $[\mathrm{kW}]$;

$c_{p}$ - coefficient of power [-];

$k^{p}$ - empirical coefficient assumed as 12 .

The coefficient $k$ is optimized to achieve highest determination coefficient $(R)$ in linear model presented in the Fig. 17. Similar methodology was used in (Gucma S., 2012).

Tab. 3. Critical wind speeds determined by the captains of ferries and coefficient power of selected ferries

\begin{tabular}{|c|c|c|c|c|c|c|}
\hline \multirow[t]{2}{*}{ Ferry } & 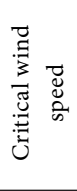 & 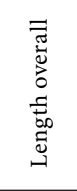 & 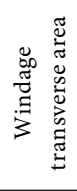 & 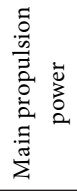 & 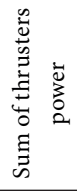 & 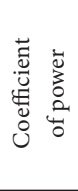 \\
\hline & $=* \frac{\tilde{\sigma}}{\Xi}$ & $\sim^{\circ} \Xi$ & 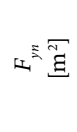 & a & $2=\bar{\sum}$ & 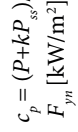 \\
\hline Gryf & 15 & 157.9 & 2890 & 7900 & 1600 & 9.4 \\
\hline Dueodde & 15 & 124.9 & 1950 & 8640 & 1000 & 10.6 \\
\hline Hammerodde & 16 & 129.9 & 2600 & 8640 & 1000 & 7.9 \\
\hline
\end{tabular}




\begin{tabular}{|c|c|c|c|c|c|c|}
\hline \multirow[t]{2}{*}{ Ferry } & 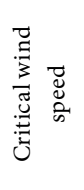 & 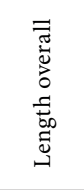 & 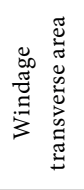 & 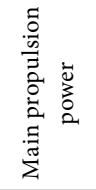 & 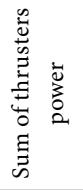 & 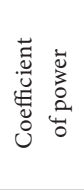 \\
\hline & $=-\frac{\infty}{\xi}$ & $\sim^{\circ} \bar{\Xi}$ & $\mathrm{L}^{\mathrm{E}} \overline{\bar{E}}$ & a & $Q^{2}$ & 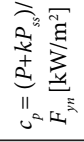 \\
\hline Mazovia (real) & 16 & 168.2 & 3900 & 17300 & 2400 & 11.8 \\
\hline Galileusz & 16 & 150.4 & 2560 & 11520 & 1500 & 11.5 \\
\hline Pomerania & 17 & 127.4 & 1940 & 12600 & 1500 & 15.8 \\
\hline Wolin & 17 & 188.9 & 3300 & 13200 & 2900 & 14.5 \\
\hline $\begin{array}{l}\text { Mazovia_2 } \\
\text { (model) }\end{array}$ & 18 & 168.2 & 3900 & 22000 & 3600 & 16.7 \\
\hline J. Śniadecki & 19 & 155.1 & 2500 & 11840 & 1500 & 11.9 \\
\hline Povl Anker & 22 & 121.2 & 2100 & 12400 & 1500 & 14.5 \\
\hline Skania & 22 & 173.7 & 3500 & 29178 & 2800 & 17.9 \\
\hline Wawel & 24 & 164.0 & 3680 & 13020 & 4200 & 17.2 \\
\hline Polonia & 24 & 169.9 & 3700 & 15840 & 6400 & 25.0 \\
\hline
\end{tabular}

For ferries identified in this study, the critical wind values will therefore be respectively:

1, Ro-Pax200m:

$c_{p}=(P+k P s s) / F_{y n}=15.0 \mathrm{~kW} / \mathrm{m}^{2}$, thus $v_{k}=0.59 c_{p}+10.2=19.0 \mathrm{~m} / \mathrm{s}$;

2. Ro-Pax230m:

$c_{p}=(P+k P s s) / F_{y n}=18.1 \mathrm{~kW} / \mathrm{m}^{2}$, thus $v_{k}=18.1 \mathrm{~m} / \mathrm{s}$.

The adopted parameters of the ferries show their high maneuverability and the possibility of operation all year round in Świnoujście (less than 1 day with wind higher than $20 \mathrm{~m} / \mathrm{s}$ ) and almost all year round in Ystad and Trelleborg (abt. 4 days with wind higher than $20 \mathrm{~m} / \mathrm{s}$ ).

It should be remembered that there are two types of maneuvers performed by ferries: static and dynamic. The first of these relies on the force and static interaction of propulsions for external extortion (mainly wind). The dynamic maneuver is to keep the ferry moving and to generate fast-changing moments of forces in order to counteract external influences.

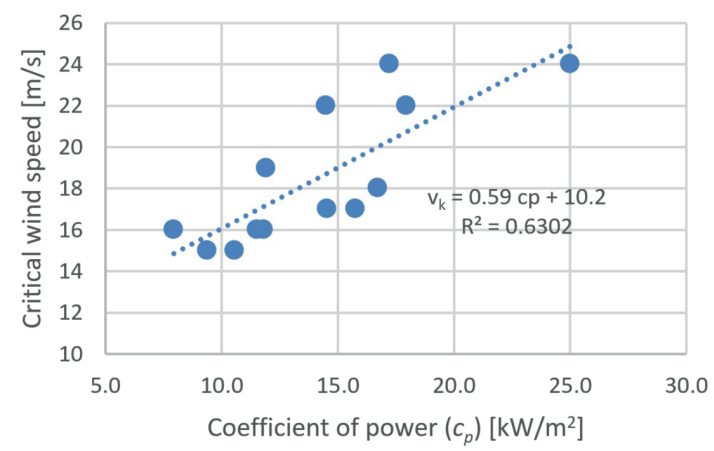

Fig. 17. Dependence of critical wind $\left(v_{k}\right)$ of selected ferries from the power coefficient $\left(c_{p}\right)$

\section{CONCLUSIONS}

The study analyzed the parameters of Ro-Pax ferries currently operated in the Baltic Sea of length overall over $150 \mathrm{~m}$. The performed analyses are vital in reference to plans of designing new vessels and modernizing port infrastructure. The trend of ferry development was determined and on its basis the parameters of two optimal ferries were determined for next 25 and 35 years of operation.

The study shows that Ro-Pax ferries on the Baltic Sea are replacing by new units relatively slowly and lot of them are still more than 20 years old.

The analysis showed that major parameter of Ro-Pax ferries is length overall. In detailed analysis the simplified models were presented which connect ferry length with other important parameters like: main engine power, thruster's power and windage area.

The development trend of the ferries was determined on this basis and the parameters of the future 25 years and 35 years were defined as:

1. The medium-maximum unit (Ro_Pax 200m) is a Ro-Pax ferry with the length $L_{o a}=200 \mathrm{~m}$ (other parameters are in the study) that can be maneuvered to the wind with a force of about $19 \mathrm{~m} / \mathrm{s}$. Such ferry, assuming that the dynamics of infrastructure development will not change significantly, could be operated on the Baltic Sea for about 25 years. Such a unit will be able to use the existing infrastructure in the Baltic Sea during this time and exchange outdated ferries.

2. The maximum-future unit (Ro_Pax $230 \mathrm{~m}$ ) with the total length $L_{o a}=230 \mathrm{~m}$ and other parameters specified in the study, which will be able to be operated only in some Baltic Sea ports and will enter slowly into operation in the perspective of several or more years.

The method of critical wind speed determination based on expert (captain's) opinion was presented. The method was applied to future ferries to find critical wind, assumed for given solution and later on economical effectiveness of ferries (yearly delay time in given route).

The study analyzed also the existing and planned port infrastructure in Świnoujście, Ystad and Trelleborg in terms of current and future capability of operating large ferries (Loa> 200m) stating the following:

- In the current state of infrastructure, it is possible to operate determined Ro-Pax $200 \mathrm{~m}$ ferry in all three analyzed ports, regardless of conditions, but only one quay is available in Świnoujście;

- On the Świnoujście - Trelleborg line it will be possible to operate the Ro_Pax 230m unit in 2020;

- On the Świnoujście - Ystad line it will be possible to operate a Ro_Pax 230m unit after 2020 or later, depending on the pace of modernization works at the Ystad Port which are about to start in 2018. 


\section{ACKNOWLEDGMENTS}

This research outcome has been achieved under the grant No 1/S/CIRM/16 financed from a subsidy of the Ministry of Science and Higher Education for statutory activities.

\section{REFERENCES}

1. Andrews, D. J. (1985) An integrated approach to ship synthesis. Trans. RINA.

2. Bertram, V. (2000) Practical Ship Hydrodynamics. Butterworth - Heinemann, Oxford.

3. Charchalis, A. (2013) Dimensional constraints in ship design. Journal of KONES Powertrain and Transport 20 (2), pp. 27-32.

4. Charchalis, A. \& Krefft, J. (2009) Main dimensions selection methodology of the container vessels in the preliminary stage. Journal of KONES Powertrain and Transport 16 (2), pp.71-78.

5. Evans, J. H. (1959) Basic Design Concept. Naval engineers Journal 71(4).

6. Gucma, L. (2010) Risk based method admittance policy of large ferries approaching to Ystad Port. Scientific Journals of the Maritime University of Szczecin 20(92), pp.33-40.

7. Gucma, S. (ed.) (2012) Sea Ferry Terminals - Designing and Exploitation in terms of Maritime Traffic. (In Polish) Gdańsk: Okrętownictwo i Żegluga.

8. Iza, V.(2003) Solutions - enhancing the ship power supplier strategy, Marine news, Wartsila, 2-2003

9. Molland, A. F. (2008) The Maritime Engineering Reference Book, Elsevier.

10. Papanikolaou, A. (2014) Ship Design. Methodologies of Preliminary Design. Springer Netherlands, Dordrecht.

11. Ro-Ro \& Ferry Atlas Europe 2016/2017

12. Schneekluth, H. \& Bertram V.(1998) Ship design for efficiency and economy. Butterworth - Heinemann, Oxford.

13. Uriasz, J. (2010) Baltic Ferry Transport. Transport Systems Telematics 104, pp.160-167.

14. Watson, D. (1998) Practical Ship Design. Elsevier Science, Oxford.

15. www.ferry-site.dk (access January - February 2017)

16. www.matkustajalaivat.com (access January-February 2017)
17. Wiskulski, T. \& Bar-Kołelis D. (2012) Passanger traffic on the Baltic Sea Region in years 2000-2011. Romanian Review on Political Geography XIV, no. 1/2012, pp. 34-44.

\section{CONTACT WITH THE AUTHORS}

\author{
Lucjan Gucma \\ e-mail:l.gucma@am.szczecin.pl \\ Maritime University of Szczecin \\ Waly Chrobrego $1 / 2$ \\ 70-500 Szczecin \\ Poland \\ Julia Raczkowska \\ e-mail:j.raczkowska@am.szczecin.pl \\ Maritime University of Szczecin \\ Waly Chrobrego 1/2 \\ 70-500 Szczecin \\ POLAND
}

